\title{
Editorial for the Special Food Summit 2008 Issue of Chemosensory Perception
}

\author{
Valesca Kooijman - Annette Stafleu - Markus Stieger • \\ Rob Hamer • John Prescott
}

Published online: 20 February 2010

(C) 2010 Springer Science+Business Media, LLC

Over recent decades, a significant amount of knowledge has been generated on flavour perception and its underlying mechanisms, in particular at the receptor level. We know fairly well by now how these processes are involved in the generation of sensory-taste, olfaction, somatosensorysignals, but flavour perception is more complex, involving not only cross-modal integration of sensory information from all senses but also influences from reward processes, expectation, memory and learning. The interplay of these factors is less well understood, but it is these aspects that are increasingly recognised as important in determining responses to foods and food choice. It is for this reason that Top Institute Food and Nutrition (TIFN) selected these complex interactions between food and the human response system as the topic for its 2008 meeting "The Taste of Sense", the tenth in the series of TIFN Food Summits.

The purpose of the TIFN Food Summits is to set the future research agenda on an important integrated topic of food research by bringing together international experts to discuss and identify major issues which limit current progress, to define new routes to overcome such issues and to stimulate collaboration. The 2008 Food Summit commenced with presentations by keynote speakers on underlying neurophysiological mechanisms of food perception and a perspective from a food engineering point of view, its current technological possibilities and limits. These lectures formed the basis for the discussion sessions which addressed questions related to (a) interactions of receptor level mechanisms, (neuro)physiological activations and cross-modal integration, in determining food perceptions; (b) the impact of the physiological state of a person (e.g. age, gender, hormone balance) on food perception and its underlying mechanisms and (c) how knowledge of these underlying mechanisms and the resulting principles of food perception can be realised and applied to food systems.

This special issue of Chemosensory Perception contains seven papers based on Food Summit presentations, including papers by two of the keynote speakers, Edmund Rolls and Tom Scott, as well as papers on topics raised in the discussion sessions by participants at the meeting.

V. Kooijman $\cdot$ A. Stafleu $\cdot$ M. Stieger $\cdot$ R. Hamer

Top Institute Food \& Nutrition,

Wageningen, The Netherlands

J. Prescott $(\square)$

University of Newcastle,

Ourimbah, Australia

e-mail: prescott18@googlemail.com 